\title{
SARTRE: TEORÍA FENOMENOLÓGICA DE LAS EMOCIONES, EXISTENCIALISMO Y CONCIENCIA POSICIONAL DEL MUNDO
}

\section{Adolfo Vásquez Rocca *}

Universidad Andrés Bello - Universidad Complutense de Madrid

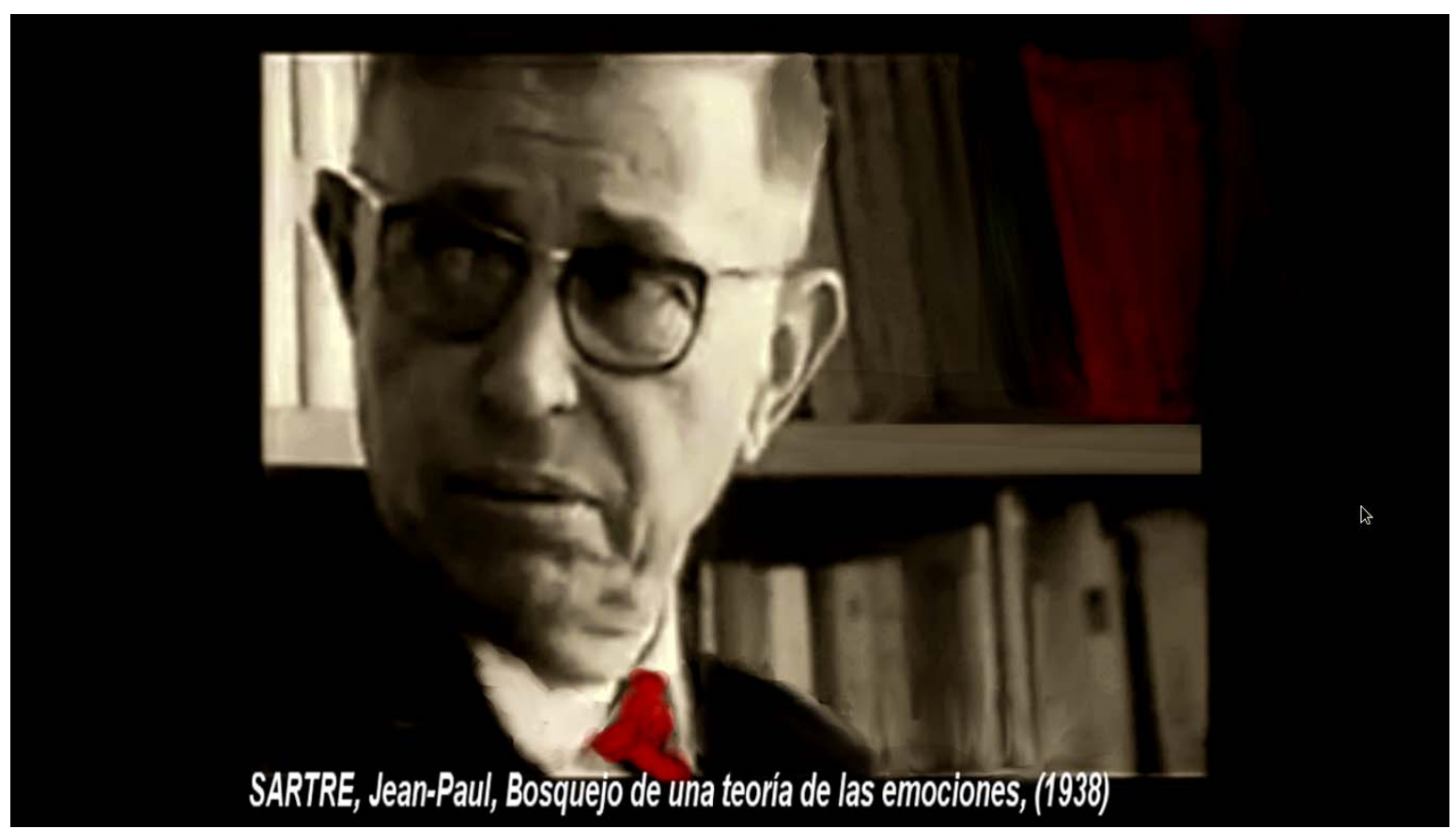


Resumen.- En el presente trabajo se trata el problema de la vivencia emocional, se indaga la naturaleza de la conciencia emotiva, es decir, la conciencia de la emoción desde una perspectiva fenomenológica, siguiendo principalmente el pensamiento de Sartre en su obra "Bosquejo de una teoría de las emociones", inserta en la tradición fenomenológica de Husserl, haciendo énfasis en las contradicciones en que incurre la teoría psicoanalítica. Se busca evidenciar cómo la conciencia emocional es ante todo "conciencia del mundo", así como la emoción es una forma organizada de la existencia humana, un modo de estar en el mundo. La conciencia se trasforma a sí misma para trasformar el mundo. La conciencia no se limita a proyectar significaciones afectivas sobre el mundo que le rodea, sino que vive en el mundo que acaba de crear.

Palabras clave.- conciencia, mundo, emoción, miedo, fenómeno, alteridad, psicología, existencialismo

\section{Sartre: Phenomenological theory of emotions, existentialism positional awareness and world.}

Abstract.- In the present work the problem is the emotional experience, investigates the nature of the touching conscience, that is to say, the conscience of the emotion from a phenomenological perspective, following mainly the thought of Sartre in its work "Sketch of a theory of the emotions", builds work follows the phenomenological tradition of Husserl, doing emphasis in the contradictions which the psychoanalytic theory incurs. One looks for to demonstrate as the emotional conscience is before "conscience of the world", and the emotion is an organized form of human existence, a way of being in the world. Consciousness itself is transformed to transform the world.

Keywords.- conscience, world, emotion, fear, phenomenon, alterity, psychology, existentialism

"La conciencia se conmueve sobre su emoción, la intensifica. Cuanto más se huye, más miedo se tiene."

Jean-Paul Sartre 


\section{1.- La Fenomenología de Husserl y la "intencionalidad". Antecedentes}

Como ya lo había anticipado Descartes y profundizado Brentano, sabemos con Husserl que los actos de conciencia poseen una estructura bipolar, esto es, correlacional. Es precisamente esta relación a algo otro el carácter relacional o lo que Husserl llama "intencionalidad de la conciencia".

Así toda conciencia queda caracterizada por apuntar a un objeto (lo percibido, lo recordado, lo amado, etc.). La conciencia en sí misma no es nada, es siempre conciencia de algo. Existe sólo en la medida en que se dirija su atención hacia un objeto, hacia una meta. Este objeto intencional está constituido por los múltiples logros sintéticos de la conciencia y aparece en su estructura general, ya sea en la percepción, la memoria o la imaginación; alrededor del núcleo, del "tema" del objeto intencional, se extiende un campo temático delimitado por un horizonte abierto. Este horizonte, en el que siempre viene dada la conciencia del propio cuerpo vivo, se puede a la vez tematizar. La secuencia de temas interrelacionados - llamémoslos "vivencias" (Erlebnisse) - no tiene, en sí, sentido. Pues las aprehensiones que no ocurren pura y simplemente, y en forma independiente, sino que atraen la atención del yo, adquieren un mayor grado de definición temática; se tornan "experiencias" claramente perfiladas. Pertenece pues a la naturaleza de la conciencia ser relación a otra cosa, una que la descripción fenomenológica deberá precisar. Así por ejemplo el acto de ver, aun en el infortunio de la alucinación, esto es, en el creer ver algo, o soñarlo, tiene lugar con referencia a una cosa, supuestamente presente. Igualmente, el acto de sufrir o el dudar poseen un modo propio de referirse a algo.

Para Husserl la intencionalidad no es sólo intrínseca a la conciencia sino a priori respecto de su objeto, lo que supone que la conciencia se funda desde sí misma, vale decir que tanto la manifestación de su objeto como la constitución de este fenómeno -la intencionalidad- se dan al unísono en la vivencia ${ }^{1}$.

En esta misma dirección apunta la obra de Merleau-Ponty ${ }^{2}$ : ideas, percepción y sentir no pueden pensarse como separados ${ }^{3}$, sino en un ensamble fenomenológico, esto es, como inherentes a la nervadura misma del acto de percibir. "Cuerpo, sentir y sentidos son relacionales: no se limitan a recibir estímulos aislados, sino que captan escenas significativas, la 'ímago' de todo un segmento de vida. (...) Esto implica una ruptura con la convicción de que las percepciones, las imágenes, las ideas se hallen almacenadas en el cerebro." ${ }^{4} \mathrm{Al}$ igual que la imagen, "la percepción tiene un carácter afectivo y motriz, no sólo

\footnotetext{
${ }^{1}$ HUSSERL, Edmund, Investigaciones lógicas I - II, Revista de Occidente, Madrid, 1967.

2 MERLEAU-PONTY, Maurice, Signes (Signos), Paris: Gallimard, 1960. Colección de ensayos. Seix Barral. Barcelona, 1964.

3 DANEY, Brenda, "Aproximación a una fenomenología de las emociones: Merleau-Ponty, la Ontología de la Carne y la propuesta de una integración", Ponencia leída en el XVI Congreso Nacional de Filosofía organizada por la Asociación Filosófica Argentina, 2013

${ }^{4}$ LÓPEZ SÁENZ, M.C. "Imaginación carnal en M. Merleau-Ponty". Revista de Filosofía. Vol. 28. № 1. 2003. P. 162.
} 
cognoscitivo, porque está determinada por la atención, las motivaciones y sentimientos del perceptor." 5

Como se ve la fenomenología de Merleau-Ponty ${ }^{6}$ es, en este sentido, profundamente inclusiva, hay una conciencia emocional que es atravesada por la encarnación, ya que cuerpo, sensaciones y sentimientos, no son fenómenos aislados, sino instancias imbricadas, variaciones de la existencia corporal, y desafía las separaciones y categorías de la ontología que la ha precedido. ${ }^{7}$

\section{2.- Sartre: La mirada del otro; conciencia y mundo}

Sartre, a su vez, tomó de la Fenomenología su principio básico, la intencionalidad de la conciencia ("la conciencia es siempre conciencia de algo"); pero criticó el idealismo y el subjetivismo de Husserl. Según Sartre el "yo" no es la conciencia trascendental, sino el conjunto unitario de la intencionalidad de la conciencia que está "fuera, en el mundo", porque "es un ente del mundo, igual que el 'yo' de otro". Las cosas no están en la conciencia, como imagen o como representación, las cosas están en el mundo. "La conciencia es conciencia posicional del mundo"8, es apertura al mundo, no es el mundo. Mediante este giro re-introdujo a la conciencia en el mundo de la existencia, permitiendo que los sufrimientos y las angustias de los hombres reales recuperaran todo su peso.

En la mayoría de la teorías psicológicas, la conciencia de la emoción se explica como si esta fuera ante todo una conciencia reflexiva, es decir como si la forma primera de la emoción -como hecho de conciencia- consistiera en aparecérsenos como una modificación de nuestro ser psíquico o, si se quiere, en ser aprehendida primero como un "estado de conciencia", lo que es un dato incontrovertible aunque irrelevante a los efectos que nos ocupan, ya que no cabe duda que siempre es posible tomar conciencia de la emoción como estructura afectiva de la conciencia y decir por ejemplo "estoy triste, tengo miedo, etc.", pero -y he aquí nuestro énfasis- el miedo no es originalmente conciencia de "tener miedo", como tampoco la percepción de este escrito es conciencia de percibir el escrito. La conciencia emocional es ante todo irreflexiva, la conciencia emocional es ante todo conciencia del mundo.

Esta tesis puede ser ilustrada con recurso a algunas observaciones: Es evidente por ejemplo- que cuando un hombre tiene celos, y dichos celos -en determinadas circunstancias- le fuerzan a espiar por la cerradura de una puerta -entregándose

\footnotetext{
${ }^{5}$ Ibid

6 MERLEAU-PONTY, Maurice, (París: Gallimard, 1945) Fenomenología de la percepción. Ed. Península, Barcelona 1975

${ }^{7}$ La reversibilidad del sentir implica siempre una génesis de sentido, un sentido que no proviene de una conciencia solitaria, sino de un entrelazo del cuerpo y del mundo.

${ }^{8}$ SARTRE, Jean-Paul, Bosquejo de una teoría de las emociones, (1938), Ed. Alianza. Madrid, 1973
} 
a esta vergonzosa acción- volcando su ser en ello, en ese momento, los celos mismos lo constituyen tanto psíquica, como corporalmente. Sin embargo este hecho es irreflexivo, es decir, no supone todavía una toma de conciencia respecto de lo vil de aquel acto. Sin embargo cuando es sorprendido en aquella acción, es decir, cuando es visto por un otro, o más precisamente, cuando él mismo se aprehende como siendo objeto de una mirada, extraña, sólo entonces, su acto se objetiva, dado que es la mirada del otro la que da consistencia a su ser, de allí que la constitución de nuestra identidad, esto es, el ver claramente dentro de nosotros mismos, nos viene dado desde fuera, por la mirada del otro, del que nos valora, nos aprecia, nos traspasa, de allí que ya no nos resulte tan extraño que Sartre señale que "el infierno son los otros", esto por la constante molestia que la presencia de los otros supone y sin embargo, no podemos pasárnoslas sin ellos.

Así, en el momento en que se toma conciencia de los celos que nos constituyen, que nos poseen, la vivencia de los celos se 'congela', de tal manera que la emoción no es la toma de conciencia de esa emoción particular, en este caso los celos. A lo que se apunta es que cuando se asume una posición reflexiva se paraliza la corriente vital del vivir como se vive naturalmente una emoción.

Es así como "la emoción es una forma organizada de la existencia humana". A partir de este marco conceptual Sartre analiza la alegría, la tristeza, la ira como formas que el ser humano adopta irreflexivamente con el fin de adoptar una posición distinta ante el mundo que le permita hacerle frente de una forma más eficaz y adaptada.

La emoción es una forma de aprehender el mundo. "El sujeto que busca la solución de un problema práctico se halla fuera, en el mundo; aprehende el mundo a cada instante, a través de todos sus actos. Si fracasa en sus intentos, se irrita; y su misma irritación es también una manera en que se le aparece el mundo". ${ }^{9}$

Según Sartre, la emoción es una transformación del mundo. Cuando el ser humano se encuentra ante un mundo urgente y difícil no puede dejar de actuar (en esta medida incluso la evasión es una actitud en la que se elimina artificialmente el problema). En su criterio, el ser humano intenta transformar el mundo a través de sus actos, y la emoción opera "en forma mágica" manipulando el mundo. Nuestra conciencia cae en esa "trampa" o espejismo, y realiza sus reflexiones a partir de esa nueva realidad que no fue creada reflexivamente.

La constitución de nuestra identidad tiene lugar desde la alteridad, desde la mirada del otro que nos objeta (y nos objetiva); un otro que nos seduce y al que seducimos, al que miramos y por el que somos vistos.

Somos, en ese sentido, seres para otros y no solo por la teatralidad y el simulacro ${ }^{10}$ propios de la vida social, sino porque la inquisidora mirada del otro que

\footnotetext{
${ }^{9}$ SARTRE, Jean-Paul, Bosquejo de una teoría de las emociones, (1938), Ed. Alianza. Madrid, 1973

10 VÁSQUEZ ROCCA, Adolfo, "Baudrillard; Cultura, Simulacro y régimen de mortandad en el
} 
nos constituye; en ella y por ella nos reconocemos. Así -frívolamente- reducimos todo lo real a mera apariencia utilitarista de nuestra personalidad ${ }^{11}$ y ya no hay esencia o como dirá Sartre "la existencia precede a la esencia". Recordemos la aguda observación de Oscar Wilde: "sólo los hombres superficiales no juzgan por las apariencias"12

Así, el yo viene a la existencia por la intermediación de la consciencia que lo constituye para significar su propia individualidad y su propia unidad. Se trata, pues de una creación originaria. El yo se distingue, también, de los caracteres de una historia o de un relato puesto que es parte de un proceso de mi consciencia; y lo es precisamente en el sentido de que aparece solamente cuando reflexionamos sobre nosotros mismos, a saber, sobre los procesos anteriores de nuestra consciencia. Cuando soy consciente de alguna cosa, no soy más que implícitamente consciente de mí. No es sino volviendo sobre mi consciencia anterior que devengo explícitamente consciente de mí, de mi yo. De esta forma, aprendo a conocerme de manera reflexiva y, por lo tanto, puedo decidir realizarme, o constituirme, como otro que el que era. Y así al infinito pues por mi consciencia yo estoy siempre en camino de mí mismo y me supero constantemente a mí mismo y no termino nunca de alcanzarme.

\section{3.- La conciencia emocional como conciencia del mundo}

La conciencia emocional es ante todo irreflexiva y en este plano sólo puede ser conciencia de sí misma en un modo no posicional, es decir cuando congela la vida y deja de ser vivida como emoción.

Sartre afirmaba que hay mundo sólo porque hay hombre. En sí mismo el mundo carece de sentido. Cuando el hombre descubre lo absurdo de lo real, su esencial contingencia y gratuidad, lo invade el sentimiento de la náusea ${ }^{13}$.

La experiencia nos muestra que la conciencia, que es conciencia del mundo, es al mismo tiempo distinta del mundo. La ontología sartreana distingue dos tipos de ser: en sí y para sí ${ }^{14}$. Las cosas son "en sí", idénticas a sí mismas (cada una es "lo

\footnotetext{
Sistema de los Objetos", En Cuaderno de Materiales, № 23, 2011, 705-714 / ISSN: 1139-4382, Universidad Complutense de Madrid UCM. http://www.filosofia.net/materiales/pdf23/CDM45.pdf

11 "Nos vestimos al caer en la cuenta de que estamos presentes ante otros, que son ajenos a nuestra (propia) interioridad. Ante esa mirada del otro configuro mi exterioridad como expresión de lo que soy. Esto nos enriquece, porque añade a nuestro ser corporal nuevos significados que expresan la riqueza interior, dándole así a nuestra apariencia (externa) una gran profundidad". En VÁSQUEZ ROCCA, Adolfo, "La Moda en la Postmodernidad. Deconstrucción del fenómeno 'fashion'", En NÓMADAS, Revista Crítica de Ciencias Sociales y Jurídicas. UNIVERSIDAD COMPLUTENSE DE MADRID, No 11 | Enero-Junio, 2005, pp. [169-176].

${ }^{12}$ WILDE, Oscar, El Retrato de Dorian Gray, (1891) Prefacio, Editorial Losada, Buenos Aires, 2005. I The Picture of Dorian Gray (Preface), Originalmente en el Lippincott's Monthly Magazine.

13 SARTRE, Jean-Paul, (1938) La Náusea, Editorial Losada, Buenos Aires, 2003.

14 SARTRE, Jean-Paul, (1943), El ser y la nada: ensayo de ontología fenomenológica, Editorial Losada, 1986, Buenos Aires.
} 
que es"). Lo "en sí" es absolutamente contingente y gratuito. Por su parte, la conciencia, que es "para sí", es "una nada de ser y, al mismo tiempo, un poder anonadador, la nada"; es "el ser para el cual en su ser está en cuestión su ser"; es "carencia de ser", que se evidencia en el deseo.

La conciencia, que está en el mundo, siendo esencialmente diferente de él, no se halla vinculada al mundo y por lo tanto es absolutamente libre. Las cosas son lo que son; la conciencia, por el contrario, no es nada, está vacía de ser, es posibilidad, es libertad. El hombre está obligado a hacerse, no tiene alternativa, está "condenado a ser libre". El ser del hombre es su "hacerse" a sí mismo. Por ello nadie llega a ser nada que no haya elegido ser.

\section{4.- Teoría Fenomenología de las Emociones.}

La conciencia emocional es ante todo conciencia del mundo, es estar volcado sobre el mundo $y$, remitiéndonos al ejemplo anterior, es ser esos vergonzosos celos que me constituían.

La conducta es irreflexiva. No es inconsciente. Es consciente de sí misma porque se trasciende y aprehende el mundo. La conciencia se trasforma a sí misma para trasformar el mundo ${ }^{15}$. "La conciencia -señala Sartre- no se limita a proyectar significaciones afectivas sobre el mundo que le rodea: vive en el mundo que acaba de crear."16

Revisemos algunos de los ejemplos que nos proporciona Sartre:

- Es evidente que el hombre que tiene miedo, tiene miedo de algo, aún tratándose de una de esas angustias imprecisas que suelen experimentarse en la oscuridad en un pasadizo siniestro. Aquí tiende a describirse erróneamente la huida con miedo como si tal huida no fuera ante todo una huida ante cierto objeto como si el objeto del que se huye no permaneciera constantemente presente en la misma huida como su tema, su razón de ser, como aquello ante lo cual se huye. En una palabra, el sujeto emocionado y el objeto emocionante se hallan unidos en una síntesis indisoluble. La emoción es una determinada manera de aprehender el mundo, una manera en que el mundo se me presenta, aunque también puede ser un intento -o un modo- de modificarlo. Aquí cabe una paradoja ya que si en los intentos de modificar o transformar el mundo se fracasa es posible y natural irritarse, de donde se puede colegir que la irritación es también una manera en que se nos aparece o presenta el mundo. Lo que aquí cabe precisar es que aún en esta operación sobre el mundo para modificarlo el sujeto no abandona el plano irreflexivo.

\footnotetext{
${ }^{15}$ SARTRE, Jean-Paul. Bosquejo de una teoría de las emociones. Ed. Alianza Editorial, Madrid, 1973.

${ }^{16}$ SARTRE, Jean-Paul. Bosquejo de una teoría de las emociones. Ed. Alianza Editorial, Madrid, 1973, P. 83.
} 
Aquí debemos notar que lo que esta en juego en estos ejemplos es la tesis fundamental de que la emoción constituye un intento de modificación del mundo. En palabras de Sartre ${ }^{17}$ que "en la emoción el cuerpo, dirigido por la conciencia, transforma sus relaciones con el mundo para que el mundo cambie sus cualidades".

Aquí es necesario decirlo, no hay mala fe, pues si bien la emoción es un juego, es un juego en el que creemos.

La conciencia, al cree en el mundo que ha creado, se hace cautiva de sí misma. Es su propio engaño. Por ello, de acuerdo al ejemplo anterior, cuanto más se huye, más miedo se tiene.

- Tomemos otro ejemplo: el miedo pasivo. Veo llegar hacia mí un animal salvaje. Mis piernas flaquean, mi corazón late más débilmente, me pongo pálido, me caigo y me desmayo. A primera vista nada menos adaptado que esa conducta que me entrega indefenso al peligro. Y sin embargo, se trata de una conducta de evasión. El desmayo es aquí un refugio. Pero no vayamos a creer que es un refugio para mí, que trato de salvarme a mí mismo de dejar de ver a la fiera. No he salido del plano irreflexivo: pero al no poder evitar el peligro por los medios normales y los encadenamientos deterministas, lo he negado. He pretendido aniquilarlo. La urgencia del peligro ha servido de motivo para una intención aniquiladora que ha impuesto una conducta mágica. $Y$ de hecho, lo he aniquilado en la medida de mis posibilidades. Estos son los límites de mi acción transformadora sobre el mundo: puedo suprimirlo en tanto que objeto de conciencia pero esto sólo lo consigo suprimiendo la conciencia misma. O, al menos, modificándola: el desmayo es, en el decir de Sartre, "el paso a una conciencia en sueños", esto es, "irrealizadora".

- Examinemos otro fenómeno emocional: La huida en el miedo activo, la cual es considerada erróneamente como una conducta racional al interpretarla como la conducta de alguien que quiere interponer la mayor distancia posible entre sí y el peligro. Si así fuera, esta conducta no sería nada más que prudencia. Sin embargo, la verdad es que no huimos para ponernos a cubierto; huimos porque no podemos aniquilarnos en el desmayo. La huida es un desmayo fingido, una conducta casi ritual que consiste en negar el objeto peligroso con todo nuestro cuerpo, trastocando la estructura vectorial del espacio en que vivimos y creando 'imaginativamente' una dirección potencial de huida hacia un reducto simbólicamente inexpugnable. La huida en el miedo activo es así una forma de negar el objeto que nos acecha. Así actúan los boxeadores novatos cuando, al abalanzarse sobre el adversario, cierran los ojos: quieren suprimir la existencia de sus puños, se niegan a percibirlos y con ello suprimen simbólicamente su eficacia.

Descubrimos de esta forma el verdadero sentido del miedo: 17 SARTRE. Jean Paul, Bosquejo de una Teoría de las Emociones, Alianza Editorial, Madrid, 1973,
pág. 88. 
El miedo es una conciencia que pretende negar, a través de una conducta mágica, un objeto del mundo exterior que aparece como amenaza, procediendo incluso a aniquilarse [a perderse] a sí misma con tal de anular la eficacia del desastre que el objeto comporta ${ }^{18}$.

- Para terminar de ilustrar la tesis que aquí nos ocupa citaremos el caso de la tristeza pasiva, la cual se caracteriza por una conducta de postración; relajación muscular, palidez, enfriamiento de las extremidades. Quien la padece se vuelve hacia un rincón y se queda sentado, inmóvil, ofreciendo al mundo la menor superficie posible. Frente a la luz del día, prefiere la penumbra; frente a los ruidos, el silencio; frente a las multitudes de los lugares públicos y de las calles, la soledad de un aposento. "Para permanecer a solas, dicen, con su dolor". Esto o es cierto. Es de buen tono, en efecto, aparentar una profunda meditación sobre la propia pena. Sin embargo, son raros los casos en que uno está apegado a su propio dolor. Tal comportamiento obedece más bien a que al desaparecer una de las condiciones habituales de nuestra acción, el mundo exige de nosotros que actuemos en él y sobre él sin esa condición. La mayoría de las potencialidades que se hallan en el mundo (trabajo que realizar, gentes que ver, actos de la vida cotidiana que llevar a cabo) siguen siendo las mismas. Pero los medios para realizarlas, las vías que surcan nuestro "espacio hodológico", han cambiado. Por ejemplo, si me he arruinado, no dispongo de los mismos medios (auto, computador, etc...) para llevarlos a cabo. He de reemplazarlos por nuevos intermediarios (tomar el bus, escribir manuscrito, etc.) y esto es precisamente lo que no quiero.

La tristeza tiende a suprimir la obligación de buscar estas nuevas vías, de transformar la estructura del mundo reemplazando la actual constitución del mundo por una estructura totalmente indiferenciada. Se trata, en buenas cuentas, de hacer del mundo una realidad afectivamente neutra, un sistema con un total equilibrio afectivo; de descargarlos objetos con fuerte carga afectiva, de llevarlos todos al cero afectivo, y, con ello, de aprehenderlos como perfectamente equivalentes e intercambiables, es decir, donde da lo mismo. En otras palabras, al no poder o querer realizar los actos que proyectábamos, procuramos que el universo ya no exija nada de nosotros.

\footnotetext{
18 Aquí se impone un paréntesis metodológico y explicativo. Debemos desconfiar de las "explicaciones" psicoanalíticas y sus supuestos, sobretodo cuando ellas insisten sobre el "hecho" que todo estado de conciencia vale por algo que no es él y que la significación del comportamiento consciente está fuera del mismo, es decir, que él mismo constituye la realización, simbólica, de un deseo reprimido. Es en este punto donde el énfasis de Sartre se orienta en otra dirección: Sartre propone atender a las condiciones de posibilidad de una emoción, no olvidando que el hombre actúa ante su mundo, no aisladamente de él. En segundo término también cabe apuntar otro supuesto de la teoría de las emociones aquí expuesta. La de que el hombre es una unidad psicofísica indisociable, idea presente ya en Aristóteles. Lo que constituye un campo abierto, altamente fructífero para el desarrollo de estrategias filosóficas y terapéuticas, donde se invite tanto a pensar desde el a pensar desde el cuerpo y concebirlo como un "escenario de representaciones", tesis que podemos encontrar en Nietzsche y Freud.
} 
Así la herida que se acaba de sufrir, un fracaso sentimental, o profesional, tal pena o duelo que afecta nuestras relaciones con el prójimo son a menudo el desencadenante, fácilmente identificable de nuestra desesperanza vital ${ }^{19}$. Una traición, una enfermedad fatal, un accidente o cualquier desgracia imprevista que nos abruma en la constante avería de lo cotidiano- y que nos arrancan repentinamente de esa categoría que nos parecía lo normal, esto es, lo de gente normal, instalándonos repentinamente en otra vida ${ }^{20}$.

Una vida insufrible, cargada de penas cotidianas, de tragos amargos, de desconsuelo solitario, a veces abrasador, otras incoloro y vacío. En suma una existencia sin vigor aunque en ocasiones exaltada por el esfuerzo realizado para continuarla, dispuesta a naufragar a cada instante en la muerte. Muerte venganza o muerte redención, será en lo sucesivo el umbral interno de nuestro agobio, el sentido imposible de esta vida cuyo peso nos parece a cada momento insostenible, excepto en los momentos en que nos movilizamos para encarar el desastre.

19 KRISTEVA, Julia, Sol negro; Depresión y melancolía, Monte Avila Editores Latinoamericana, Caracas. 1991.

${ }^{20}$ VÁSQUEZ ROCCA, Adolfo, "Peter Sloterdijk: Espacio tanatológico, duelo esférico y disposición melancólica" En NÓMADAS, Revista Crítica de Ciencias Sociales y Jurídicas ISSN 1578-6730 UNIVERSIDAD COMPLUTENSE DE MADRID, | No 17 | Enero-Junio $2008-1^{\circ}$ |, pp. 151-158 


\section{4.- Excurso en torno a La Metamorfosis de Franz Kafka y la estructura indiferenciada del mundo}

A propósito de estas últimas consideraciones "que el mundo ya no exija nada de nosotros", podemos establecer una relación entre este estado de tristeza pasiva que no es más que un intento de transformar la estructura del mundo en una estructura totalmente indiferenciada- y el acontecer dramático al interior de La Metamorfosis, el reato de Kafka donde el protagonista -Gregor Samsa- un vendedor viajero, una mañana, tras un sueño intranquilo, se encuentra en su casa convertido en un insecto ${ }^{21}$. La historia que sigue es la narración de los aparentes esfuerzos de Samsa para ajustarse a su nueva y extraña condición, la que paradojalmente le exime -al imposibilitarlo- de responder a las obligaciones propias de su condición de "pequeño burgués", agravada por el peso de ser el sostén de su familia, de sus padres y demás parientes, los cuales actúan al comienzo con preocupación (al prever que esta condición medirá al joven Samsa mantener la solvencia del hogar) y más tarde con indiferencia, crueldad y olvido. Gregor Samsa, en tanto, se distancia 'mágicamente' de las obligaciones que un mundo exterior en pleno orden y fiel a las exigencias que el establishment consagra, se esfuerza en satisfacer las demandas encarnadas por el jefe que aparece a certificar los trámites que forman parte un implacable protocolo, un último gran rito preservador de la normalidad. Pero Gregor Samsa está en las penumbras de sus "zozobras metafísicas" paralizado, en un estado de indiferencia habiendo neutralizado al mundo de sus exigencias.

Finalmente, y a modo de síntesis es necesario precisar la noción sartreana de la emoción. Podemos preguntarnos cómo surge la emoción y paralelamente con ello en qué consiste una emoción. Podemos responder que la emoción es una transformación del mundo cuando los caminos trazados se hacen demasiado difíciles o cuando no vislumbramos caminos ya no podemos permanecer en un mundo tan urgente y difícil. Todas las vías están cortadas y sin embargo hay que actuar. Tratamos entonces de cambiar el mundo o sea de vivirlo como si la relación entre las cosas y sus potencialidades no estuvieran regidos por unos procesos deterministas sino mágicamente o bien por la posibilidad de ser construidos por nosotros o reconstruidos. No se trata de un juego, nos vemos obligados a ello y nos lanzamos hacia esa actitud con toda la fuerza de que disponemos.

${ }^{21}$ KAFKA, Franz, La Metamorfosis, Ed. Cátedra, S.A. Madrid, 1994. 


\section{Adolfo Vásquez Rocca}

Doctor en Filosofía por la Pontificia Universidad Católica de Valparaíso; Postgrado Universidad Complutense de Madrid. Profesor de Postgrado del Instituto de Filosofía de la Pontificia Universidad Católica de Valparaíso; Profesor Profesor Adjunto Escuela de Psicología UNAB. -Miembro del Consejo Editorial Internacional de la 'Fundación Ética Mundial' de México. Director del Consejo Consultivo Internacional de 'Konvergencias', Revista de Filosofía y Culturas en Diálogo, Argentina. Miembro del Consejo Editorial Internacional de Revista Praxis -Facultad de Filosofía y Letras, Universidad Nacional UNA, Costa Rica. Miembro del Conselho Editorial da Humanidades em Revista, Universidade Regional do Noroeste do Estado do Rio Grande do Sul, Brasil y del Cuerpo Editorial de Sophia -Revista de Filosofía de la Pontificia Universidad Católica del Ecuador-. Secretario Ejecutivo de Revista Philosophica PUCV. -Asesor Consultivo de Enfocarte -Revista de Arte y Literatura- Cataluña / Gijón, Asturias, España. Miembro del Consejo Editorial Internacional de 'Reflexiones Marginales' -Revista de la Facultad de Filosofía y Letras UNAM. -Miembro del Comité Editorial de International Journal of Safety and Security in Tourism and Hospitality, publicación científica de la Universidad de Palermo. -Miembro Titular del Consejo Editorial Internacional de Errancia, Revista de Psicoanálisis, Teoría Crítica y Cultura UNAM- Universidad Nacional Autónoma de México. -Miembro de la Federación Internacional de Archivos Fílmicos (FIAF) con sede en Bruselas, Bélgica. Director de Revista Observaciones Filosóficas. Profesor visitante en la Maestría en Filosofía de la Benemérita Universidad Autónoma de Puebla. - Profesor visitante Florida Christian University USA y Profesor Asociado al Grupo Theoria - Proyecto europeo de Investigaciones de Postgrado -UCM. Eastern Mediterranean University - Academia.edu. Académico Investigador de la Vicerrectoría de Investigación y Postgrado, Universidad Andrés Bello. -Investigador Asociado y Profesor adjunto de la Escuela Matríztica de Santiago -dirigida por el Dr. Humberto Maturana. Consultor Experto del Consejo Nacional de Innovación para la Competitividad (CNIC)- Ha publicado entre otros el Libro: Peter Sloterdijk; Esferas, helada cósmica y políticas de climatización, Colección Novatores, № 28 , Editorial de la Institución Alfons el Magnànim (IAM), Valencia, España, 2008. Invitado especial a la International Conference de la Trienal de Arquitectura de Lisboa | Lisbon Architecture Triennale 2011. Traducido al Francés - Publicado en la sección Architecture de la Anthologie: Le Néant Dans la Pensée Contemporaine . Publications du Centre Français d'Iconologie Comparée CFIC, Bès Editions , París, (C) 2012 


\section{BIBLIOGRAFÍA}

\section{Madrid, 1967}

HUSSERL, Edmund, Investigaciones lógicas I - II, Revista de Occidente,

MERLEAU-PONTY, Maurice, Signes (Signos), Paris: Gallimard, 1960. Colección de ensayos. Seix Barral. Barcelona, 1964.

- MERLEAU-PONTY, Maurice, (París: Gallimard, 1945) Fenomenología de la percepción. Ed. Península, Barcelona 1975

- SARTRE, Jean-Paul, Bosquejo de una teoría de las emociones, (1938), Ed. Alianza. Madrid, 1973.

- $\quad$ SARTRE, Jean-Paul, (1938) La Náusea, Editorial Losada, Buenos Aires, 2003.

- SARTRE, Jean-Paul, Lo imaginario. Psicología fenomenológica de la imaginación (L'imaginaire. Psychologie phénoménologique de l'imagination, 1940)

- SARTRE, Jean-Paul, (1943), El ser y la nada: ensayo de ontología fenomenológica, Editorial Losada, 1986, Buenos Aires.

- $\quad$ KAFKA, Franz, La Metamorfosis, Ed. Cátedra, S.A. Madrid, 1994.

- WILDE, Oscar, El Retrato de Dorian Gray, (1891) Prefacio, Editorial Losada, Buenos Aires, 2005. I The Picture of Dorian Gray (Preface), Originalmente en el Lippincott's Monthly Magazine.

- HOPENHAYN, Martín, ¿Por qué Kafka? poder, mala conciencia y literatura, Buenos Aires, Paidós, 1983.

- KRISTEVA, Julia, Sol negro; Depresión y melancolía, Monte Avila Editores Latinoamericana, Caracas. 1991. 